\title{
Response to "Youth Health Services, Development Programs, and Teenage Birth Rates in 55 California Cities,”
}

\author{
Norman A. Constantine ${ }^{1}$ and Carmen R. Nevarez ${ }^{2}$ \\ ${ }^{1}$ Public Health Institute, and University of California, Berkeley \\ ${ }^{2}$ Public Health Institute
}

(C) 2006 Californian Journal of Health Promotion. All rights reserved.

In "Youth health services, development programs, and teenage birth rates in 55 California cities" [2006, 4(1):46-57], Mike Males concludes that "lower-income teens have greater access to health, sexuality education, and development services, and the availability of these services is not associated with lower rates of or greater reductions over time in teenage birth rates." We argue that these conclusions are not supported by the data, and that the analyses and causal reasoning that Dr. Males employs are flawed in several fundamental ways.

The Reality Check services indicators that Dr. Males refers to were developed by Get Real About Teen Pregnancy and the California Adolescent Health Collaborative (2004) to classify California cities into four quartiles for the explicit purposes of description and goal setting. These indicators, derived from sums of quartile ranks, were not designed nor validated for use in program evaluation or statistical analysis, and do not have the statistical and psychometric properties necessary for valid analyses.

Furthermore, Dr. Males' analyses employed the unadjusted sums of quartiles for numbers of health services and developmental measures. These raw scores had been originally calculated as an intermediate step in deriving the final and well-publicized Reality Check total scores. While the Reality Check scores were appropriately adjusted for each a city's teen population, the health and developmental service sums that Dr. Males analyzed were not. This would be like comparing the number of teen births for Los Angeles versus Chico, rather than the more informative teen birth rate of each city. Similarly, the fact that Los Angeles has more health services available than Chico is unremarkable, unless the comparison is done per capita or via some other adjustment for population.

We replicated Dr. Males' analyses using the appropriately adjusted Reality Check total scores, and also using the health and developmental services quartile sums, but divided by the city's population quartile. Although we recognize the limitations of any statistical analyses with these descriptive data, we note that the positive correlations Dr. Males found between services and teen birth rates across cities actually reversed -- now the correlations are negative, and statistically significant. In other words, high levels of services are actually associated with lower teen birth rates. This is surely an intriguing finding given both the weak psychometric properties of the scores, and as Dr. Males noted, the fact that public funding for services tends to be focused on areas with higher teen birth rates.

It is also worth noting that the Reality Check indicators were largely based on publicly funded services, and do not take in to account school-based sexuality education, nor the vast network of private health care and prevention services that tend to be inversely associated with poverty and teen birth rates. To conclude that "lower-income teens have greater access to health, sexuality education, and development services" is misleading and incorrect. 
Finally, we wish to note that Dr. Males incorrectly cited our No Time for Complacency report (Constantine and Nevarez, 2003) in both the 2002 citation date he provided, as well his use of quotes and page numbers from the separate executive summary rather than the more complete full report. In the full report, we more extensively discussed poverty as a key factor behind teen births (pages 2, 12-13), even citing Dr. Males previous work. We also demonstrated statistically that "there are additional factors jointly affecting the year-to-year variation in both poverty and teen birth rates (in addition to) the direct predictive effect of poverty on teen birth rates over time.”

Dr. Males began his article with a useful reminder of the fundamental causal role that poverty and income disparity play in teen births, a message that we agree needs to be better heard. Males has been a strong proponent of this message for many years, and for this we sincerely commend him. Yet the ambitious long-term goal of reducing or eliminating poverty and income inequality surely does not preclude the immediate need for publicly-funded health and developmental services to teens and adults. We believe that it would be appropriate and important for Dr. Males to publicly retract his misleading and unsupported conclusions identified above.

Respectfully,

Norman A. Constantine

Public Health Institute, and University of California, Berkeley

Carmen R. Nevarez

Public Health Institute

\section{References}

Constantine, N. A. \& Nevarez, C. R. (2003). No time for complacency: Teen births in California. Berkeley, CA: Public Health Institute. Retrieved April 4, 2006, from http://teenbirths.phi.org/TeenBirthsFullReport.pdf

Get Real About Teen Pregnancy \& The California Adolescent Health Collaborative. (2004). Teen birth rate declines, but challenges loom for California cities. Retrieved April 4, 2006, from http://www.letsgetreal.org/nr_RealityCheckCities_2004.htm 